\title{
Influence of rheumatoid factor in coalminers' pneumoconiosis in the Fujian Shaowu colliery, South China
}

\author{
Yi-biao Yeh, Yu-rong Lai
}

Coalminers' pneumoconiosis may be complicated by the development of progressive massive fibrosis (PMF) or by rheumatoid pneumoconiosis (Caplan's syndrome). ${ }^{12}$ The arthritis in Caplan's syndrome may precede, coincide with, or follow the development of pulmonary radiological shadows. These conditions are common in miners and may be seen in workmen exposed to dusts other than coal. ${ }^{3-5}$

The Fujian Shaowu colliery was built in 1958 . With improvements in mining technique the density of coalmine dust in the air at the workface decreased. The silicon component of coalmine dust was found to be $6 \cdot 72 \%$. After the improvements the average density of coalmine dust in the air was $10 \mathrm{mg} / \mathrm{m}^{3}$, which is low. Patients with pneumoconiosis were still found and the cases deteriorated. We think the presence of the rheumatoid factor may have been a promoting factor. We have studied these patients.

\section{Material and methods}

A total of 416 miners in the pit, aged $20-55$, having worked for five to 35 years were studied and compared with 64 surface workers of the same age range and years of work who were not exposed to coal dust. After physical examination of both groups blood was withdrawn for haematological examination and tested for rheumatoid factor (RF).

A series of chest $x$-ray films was analysed using the Diagnostic Standard of Pneumoconiosis of the People's Republic of China. The subjects were graded according to the speed of advance of the pulmonary lesions as shown in the $x$ ray films.

We measured the pulmonary ventilating function in the pitminers with the Japanese made HI-298 miniature apparatus.

\section{Results}

Among the 416 pitminers $132(31 \cdot 73 \%)$ were found to be RF positive. The rate decreased, however, with decreasing years of work in the pit (figure). Among

Teaching Group of Occupational Medicine, Department of Public Health, Fujian Medical College, Fujian, People's Republic of China

Y-b Yeh, Y-r Lai the 64 surface workers the RF test was negative in all cases. Among the RF positive subjects no typical sufferers from rheumatoid arthritis were found.

Of the 416 miners, 85 suffered from pneumoconiosis and of these, $37(43.5 \%$ ) were RF positive. Of the 331 subjects without pneumoconiosis, 95 $(28.7 \%)$ were RF positive (table 1$)$. The aetiological relation between RF and pneumoconiosis is shown in the difference between the percentages of RF positive subjects in the pneumoconiosis group and the non-pneumoconiosis group $(p<0.01)$.

In 259 miners, each with a series of chest $x$ ray films, the speed of progression of pulmonary lesions appeared to be more rapid in RF positive subjects than in RF negative subjects (table 2).

In patients in the early stages of pneumoconiosis the relation of $R F$ to pulmonary ventilation function was shown in tests of the $F E V_{1} / F V C$ ratio and of the mean maximum expiratory flow between $25 \%$ and $75 \%$ of the forced vital capacity $\left(\mathrm{MMEF}_{25-75}\right)$. No obvious influence was found (table 3 ).

\section{Discussion}

Occupational contact with coalmine dust may convert the serum RF test from negative to positive. It is thought that silica (silicon dioxide) in the coalmine dust induces the seroconversion. Coal dust alone is not considered to have any special function with

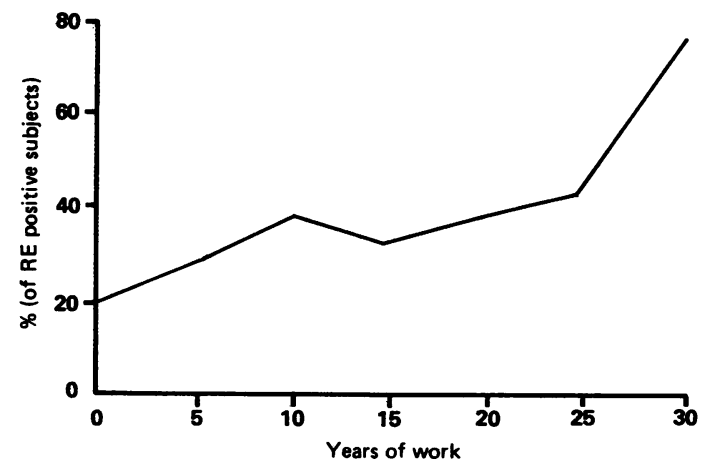

Distribution of percentages of $R F$ positive subjects according to years of work in the pit. 
Table 1 Comparison of percentage of $R F$ positive subjects among sufferers from pneumoconiosis and sufferers without pneumoconiosis in 416 pitminers $(p<0.01)$

\begin{tabular}{lccc}
\hline Subjects & RF positive & RF negative & Total \\
\hline Pneumoconiosis & $37(43.5 \%)$ & 48 & 85 \\
Non-pneumoconiosis & $95(28.7 \%)$ & 236 & 331 \\
Total & $132(31.73 \%)$ & 284 & 416 \\
\hline
\end{tabular}

Table 2 Relation between positive RF and development of pulmonary lesions shown in serial chest $x$ ray films in 259 pitminers $(p<0.01)$

\begin{tabular}{lcllcc}
\hline$R F$ & $\begin{array}{l}\text { Obviously } \\
\text { advanced }\end{array}$ & Advanced & $\begin{array}{l}\text { Slightly } \\
\text { advanced }\end{array}$ & Stable & Total \\
\hline Positive & 22 & 41 & 10 & 12 & 85 \\
Negative & 0 & 14 & 23 & 137 & 174 \\
Total & 22 & 55 & 33 & 149 & 259 \\
\hline
\end{tabular}

regard to $\mathrm{RF} .{ }^{6}$ Coalmine dust inhaled into the lungs is swallowed by phagocytes to form dust cells. These break down, change their nature, and release large amounts of liquid enzyme. The enzyme causes globulin to alter its nature. When the altered globulin is recognised by the organism RF is produced.

There is a close relation between immunity and pneumoconiosis. The nodules in pneumoconiosis and the patient's serum have been analysed: globulin was found to be increased and complement decreased. $^{7}$ This supports the concept that the organism in contact with coalmine dust sustains immunological change and produces RF.

Immunological factors, as shown by the presence of RF, may promote the development of pulmonary lesions. Caplan et al noted that when pneumoconiosis occurs with rheumatoid arthritis the pulmonary lesions progress quickly and this has been widely confirmed. ${ }^{2}$ Chiappino and Vigliani studied the various factors influencing the development of pneumoconiosis and recognised the importance of immunology.$^{8}$ Hobbs et al showed that in the serum during antibody reactions in the organism RF increased the numbers of immunoglobulin secreting cells. ${ }^{9}$ Patients with pneumoconiosis who are RF positive develop unexpectedly massive pulmonary

Table 3 Influence of $R F$ on pulmonary ventilation function studies in the early stage of pneumonociosis in $47 R F$ negative subjects and $38 R F$ positive subjects

\begin{tabular}{llll}
\hline Investigation & $\begin{array}{l}\text { RF negative } \\
\text { subjects }\end{array}$ & $\begin{array}{l}\text { RF positive } \\
\text { subjects }\end{array}$ & p value \\
\hline VC (ml) & $3404 \cdot 2 \pm 639 \cdot 27$ & $3306 \cdot 5 \pm 53 \cdot 22$ & $>0 \cdot 05$ \\
FEV $_{1} / \mathrm{FVC}$ & $73 \cdot 1 \% \pm 10 \cdot 12$ & $69 \cdot 7 \% \pm 14 \cdot 14$ & $>0.05$ \\
MMEF $_{25-75}(\mathrm{l})$ & $2 \cdot 27 \pm 0.683$ & $2 \cdot 28 \pm 0.897$ & $>0.05$ \\
\hline
\end{tabular}

lesions. The speed of development has been faster than in patients with PMF who are RF negative. We have found this in an analysis of our cases.

We found that the pulmonary ventilating function was little affected in patients with early pneumoconiosis. This corresponds with the report by Lyons and Campbell. ${ }^{10}$ But patients with RF positive pneumoconiosis are prone to chronic pulmonary infections ${ }^{11}$ and will leave the labour force earlier than they otherwise might have done. In view of this it is important to prevent the early onset of RF positive pneumoconiosis and maintain the miners' labour force.

With regard to the treatment of pneumoconiosis, prevention is all important, such as the suppression of coal dust formation in the mines and the finding of alternative employment in progressing cases. Adrenocorticotropic and antituberculous drugs are traditionally used. Alkylating drugs and antimetabolites are sometimes used, though their efficiency is uncertain. ${ }^{12}$ The Chinese medicinal herb Pritriypium wilfordii has been used clinically and we have found it promising. Controlled clinical trials are needed. Whether it has any preventive action is as yet unknown.

1 Caplan A. Certain unusual radiological appearances in the chest of coal-miners suffering from rheumatoid arthritis. Thorax 1953;8:29-37.

2 Caplan A, Payne RB, Withey JL. A broader concept of Caplan's syndrome related to rheumatoid arthritis. Thorax 1962; 17:205-12.

3 Price TML, Skelton MD. Rheumatoid arthritis with lung lesions. Thorax 1956;11:234-40.

4 Gough J, Rivers D, Seal RME. Pathological studies of modified pneumoconiosis in coal-miners with rheumatoid arthritis (Caplan's syndrome). Thorax 1955;10:9-18.

5 Antilla S, Sutimen S, Paakko P, Finell B. Rheumatoid pneumoconiosis in a dolomite worker: a light and electron microscopic and $x$-ray microanalytical study. $B r J$ Dis Chest 1984;78:195-200.

6 Gross P, Braun DC, de Treville RTP. The pulmonary response to coal dust. In: Selikoff IJ, Key MM, Lee DHK, eds. Coal workers' pneumoconiosis. Ann NY Acad Sci 1972;200: 155-65.

7 Chang QF. Pneumoconiosis and immunity, prevention and treatment of pneumoconiosis and tuberculosis in miners. Shanghai: Enery Research Publishing House, 1985:90-108. (In Chinese.)

8 Chiappino G, Vigliani EC. Role of infective immunological and chronic irritative factors in the development of silicosis. $\mathrm{Br} J$ Ind Med 1982;39:253-8.

9 Hobbs MV, Morgan EL, Baker NL, Weigle WD. Regulation of antibody reponses by rheumatoid factor. J Immunol 1985; 134:223-9.

10 Lyons JP, Campbell $\mathrm{H}$. Relation between progressive massive fibrosis, emphysema, and pulmonary dysfunction in coalworkers' pneumoconiosis. Br J Ind Med 1981;38:125-9.

11 Cooke NT, Bamii AN, Banks RA, Young KA. Rheumatoid arthritis and chronic suppurative lung disease. Thorax 1981; 36:229-30.

12 Davies D. Disability, survival, and coalworkers' pneumoconiosis. Br Med J 1973;ii:773-4.

Accepted 18 May 1989 